\title{
Performance Analysis of a Hybrid Power Cutting System for Roadheader
}

\author{
Yang Yang, Guowei Li, and Aihui Yuan \\ State Key Laboratory of Mechanical Transmission, Chongqing University, Chongqing 400044, China \\ Correspondence should be addressed to Yang Yang; yangyang@cqu.edu.cn
}

Received 18 January 2017; Accepted 28 February 2017; Published 21 March 2017

Academic Editor: Mohammed Nouari

Copyright (c) 2017 Yang Yang et al. This is an open access article distributed under the Creative Commons Attribution License, which permits unrestricted use, distribution, and reproduction in any medium, provided the original work is properly cited.

\begin{abstract}
An electrohydraulic hybrid power cutting transmission system for roadheader under specific working condition was proposed in this paper. The overall model for the new system composed of an electric motor model, a hydraulic pump-motor model, a torsional planetary set model, and a hybrid power train model was established. The working mode characteristics were simulated under the conditions of taking the effect of cutting picks into account. The advantages of new hybrid power cutting system about the dynamic response under shock load were investigated compared with the traditional cutting system. The results illustrated that the hybrid power system had an obvious cushioning in terms of the dynamic load of cutting electric motor and planetary gear set. Besides, the hydraulic motor could provide an auxiliary power to improve the performance of the electric motor. With further analysis, a dynamic load was found to have a high relation to the stiffness and damping of coupling in the transmission train. The results could be a useful guide for the design of cutting transmission of roadheader.
\end{abstract}

\section{Introduction}

Currently, the ever-increasing application of roadheader in the underground is becoming an inevitable alternative in tunnel excavation and coal mining engineering. And it also plays a significant role among other excavation machines for civil construction and resource exploitation. With the advancements of technology in both civil and mining construction fields, roadheader has been the focus of considerable interest because of the unique characterizations, including high efficiency, safety, flexibility, the ability to excavate almost any profile opening, and intelligence. And the electrohydraulic hybrid power cutting transmission system for roadheader proposed in this paper has been authorized to obtain the invention patent from State Intellectual Property Office of China [1]. Ocak and Bilgin stated that the performance of roadheader was higher in terms of tunnel completion time and production efficiency compared with impact hammer [2].

Underground coal seam exploitation is constantly becoming much deeper in recent years with respect to hundreds of kilometers of metallic ores and coal, industrial tunnels. Mechanics environments of rock in the deep excavation are characterized by high temperature, high pressure, and high permeability [3]. Based on the mentioned situation, the significant deformation of coal and rock mass can be observed, ranging from brittle in shallow mining to ductile in deep mining. The deformation of rock and mass with a discontinuous shock impact appears to be obvious rheology or creep under high initial stress. The strength of coal and rock mass is a basic parameter in the study of rock mechanics [4]. The strength presents the obvious fluctuation due to native injury, anisotropy, heterogeneity, and partial distribution of structural weakness planes, which results in enormous impacts on speed of excavation, attrition of cutting pick, failure of transmission chain, and service life of motors [5].

In order to bring the advantage of roadheader into full play and enhance the design efficiency, the researchers focused on performance prediction on the basis of rock features $[6,7]$. Bilgin et al. developed a performance equation below [8]:

$$
\begin{aligned}
\mathrm{ICR} & =0.28 \times P \times(0.974)^{\mathrm{RMCI}}, \\
\mathrm{RMCI} & =\sigma_{c} \times\left(\frac{\mathrm{RQD}}{100}\right)^{2 / 3},
\end{aligned}
$$


where ICR, $P$, RMCI, $\sigma_{c}$, and RQD denote the instantaneous cutting rate ( $\mathrm{m}^{3} /$ cutting hour), the power of cutting head, the rock mass cuttability index, the uniaxial compressive strength $(\mathrm{MPa})$, and the rock quality designation (\%), respectively.

Balci et al. suggested a performance prediction model considering the energy transfer ratio of roadheader cutting head in addition to UCS and $P$ given in (2) for transverse and (3) for axial type roadheaders [9]:

$$
\begin{aligned}
& \mathrm{ICR}=k \times \frac{P}{0.37 \times \mathrm{UCS}^{0.86}}, \\
& \mathrm{ICR}=k \times \frac{P}{0.41 \times \mathrm{UCS}^{0.67}},
\end{aligned}
$$

where ICR is the instantaneous cutting rate in $\mathrm{m}^{3} / \mathrm{h}, P$ is the installed cutting head power in $\mathrm{kW}$, UCS is the uniaxial compressive strength in $\mathrm{MPa}$, and $k$ is the energy transfer ratio.

Many researchers are still focusing on refining the performance prediction of roadheader. However, the classical regularity never changes such as the negative correlation between the strength of rock and coal mass and cutting rate. But beyond that, cutting head power is in proportion to cutting rate. Hence, as for the deep tunnel excavation, there is a positive correlation between the stronger cutting head power and the driving speed. Moreover, the strength of rock and coal mass also had an influence on stability and reliability, which can directly affect the production efficiency. The failure of roadheader's cutting unit is mainly caused by overall vibration, the main manifestations of which are the attrition of cutting picks, the damage of gears, and the breakdown of the hydraulic system [10-12]. The vibration sources are as follows:

(1) In cutting process, picks are subjected to nonlinear instantaneous shock load, especially semicoal rock or hard rock.

(2) The vibration of gears is caused by internal excitation such as time-varying meshing stiffness.

(3) The roughness of vertical section in roadway causes that the distribution of crawler's support is far from uniform.

(4) Connection looseness of vital components, the poor lubrication of transmission system, the wear of bearings, and the fatigue failure.

In summary, the characteristics of coal and rock are the research hotspot at present, and the research for the roadheader itself is less. In order to further improve the stability and reliability of roadheader in severe working conditions, a hybrid power cutting transmission system with a parallel cutting motor and a parallel hydraulic motor is proposed in this paper based on the structure characteristics of roadheader. The dynamic characteristics of cutting transmission system were specifically analyzed in the following.

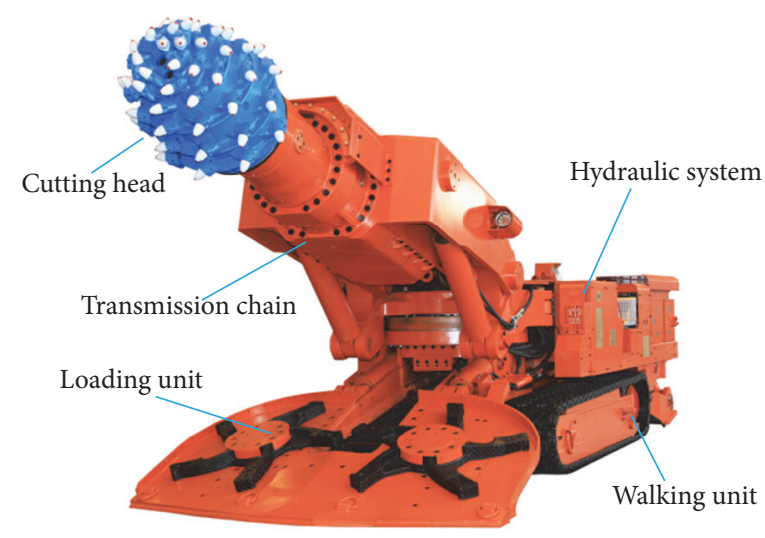

FiguRE 1: Boom-type roadheader.

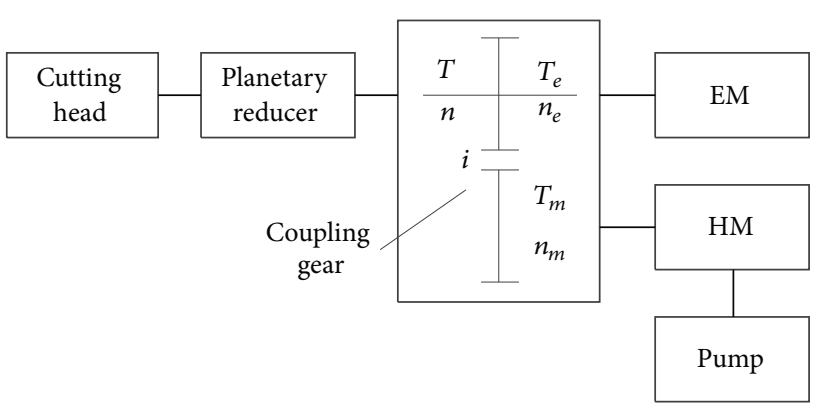

FIgURE 2: Parallel torque coupling system.

\section{Description of the Hybrid Power Cutting Transmission System}

Restricted to the underground space and the size of highpowered explosion-proofing motor, promoting the cutting power brings a huge challenge for the design and performance of the whole machine while the cutting power of roadheader is generally approximately $250 \mathrm{~kW}$. The traditional roadheader, as shown in Figure 1, mainly consist of a cutting unit, a loading unit, a transportation department, a walking unit, a cooling and a dedusting system, electrical systems, and other components. And the cutting unit is driven by electric motor (EM) while other parts are driven by hydraulic system. The cutting unit is the core part of roadheader, including cutting motor, gear reducer, cantilever, and cutting head. Walking unit is mainly responsible for the shunting around, whose power configuration was about $70 \mathrm{~kW}$.

One of the characteristics for roadheader is that walking unit will suspend when the machine is cutting coal and rock mass. After ending the cutting position location at the beginning of one working cycle, walking unit brakes and the cutting head inserts into working face. Therefore, it is feasible to reuse the power of walking unit to cutting system through a torque coupling mechanism at the specific condition of cutting. As a consequence, a parallel hydraulic hybrid power cutting transmission system is put forward, as shown in Figure 2. A coupling gear is employed to combine input power between electric motor (EM) and hydraulic motor (HM). The 


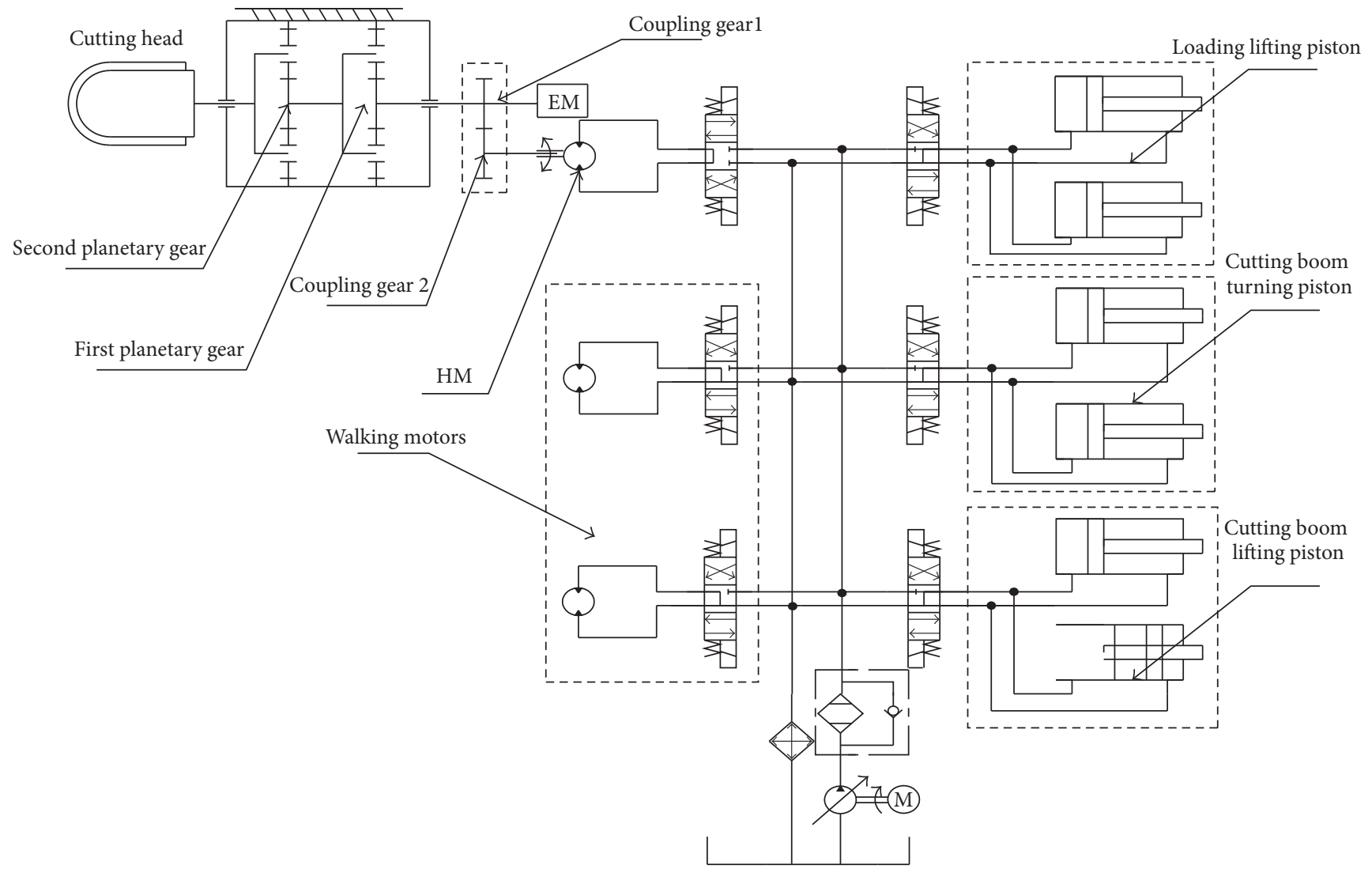

Figure 3: Schematic diagram of the system.

reducer, comprising two-stage planetary gear sets with sun gear input and carrier output, provides the output power to cutting head.

As depicted in Figure 3, it is the schematic diagram of the new system. A variable displacement pump-variable displacement motor hydraulic circuit is adopted in this system. The output torque of HM is controlled by means of changing the displacement while the pressure is constant. There are three working modes for the new system to deal with different working conditions:

(1) For light load, cutting electric motor works singly. The displacement of HM is adjusted to minimum.

(2) For normal load, cutting electric motor and cutting hydraulic motor work simultaneously. The displacement of HM is changed corresponding to the load. The rotate speeds of HM and EM are almost unchangeable because of the parallel relationship between them. Thus, changing the output torque of HM can adjust the output power allocation between HM and EM. As a result, EM can work around the rated power point with a high efficiency.

(3) For heavy load, cutting electric motor and cutting hydraulic motor work simultaneously and the displacement of HM is adjusted to maximum.

\section{Models of Transmission System}

3.1. Electromechanical Model of Transmission System. Figure 4 indicates the overall model of the hybrid power cutting transmission system which consists of traditional cutting system, coupling gears, and hydraulic system. The dynamics differential equations of the new hybrid power system are as follows [13]:

$$
\begin{aligned}
I_{e} \ddot{\theta}_{e}+k_{e}\left(\theta_{e}-\theta_{s 1}\right)+c_{e}\left(\dot{\theta}_{e}-\dot{\theta}_{s 1}\right) & =M_{e}, \\
I_{m} \ddot{\theta}_{m}+k_{m}\left(\theta_{m}-\frac{\theta_{s 1}}{i}\right)+c_{m}\left(\dot{\theta}_{m}-\frac{\dot{\theta}_{s 1}}{i}\right) & =M_{m}, \\
I_{n} \ddot{\theta}_{n}+k_{n}\left(\theta_{n}-\theta_{c 2}\right)+c_{n}\left(\dot{\theta}_{n}-\dot{\theta}_{c 2}\right) & =M_{c}, \\
T_{s 1} & =T_{e}+i T_{m}, \\
T_{s 1} i_{1} & =T_{s 2}=\frac{T_{c 2}}{i_{2}}, \\
\theta_{c 2} & =\frac{\theta_{s 1}}{i_{1} i_{2}},
\end{aligned}
$$

where $I_{e}, I_{m}$, and $I_{n}$ are the rotary inertia of the EM, HM, and cutting head, respectively; $M_{e}$ and $M_{m}$ are input torque of EM and HM; $M_{c}$ is the load torque; $T_{e}$ is the torque input to coupler $1 ; T_{m}$ is the torque input to coupler $2 ; T_{s 1}$ is the 


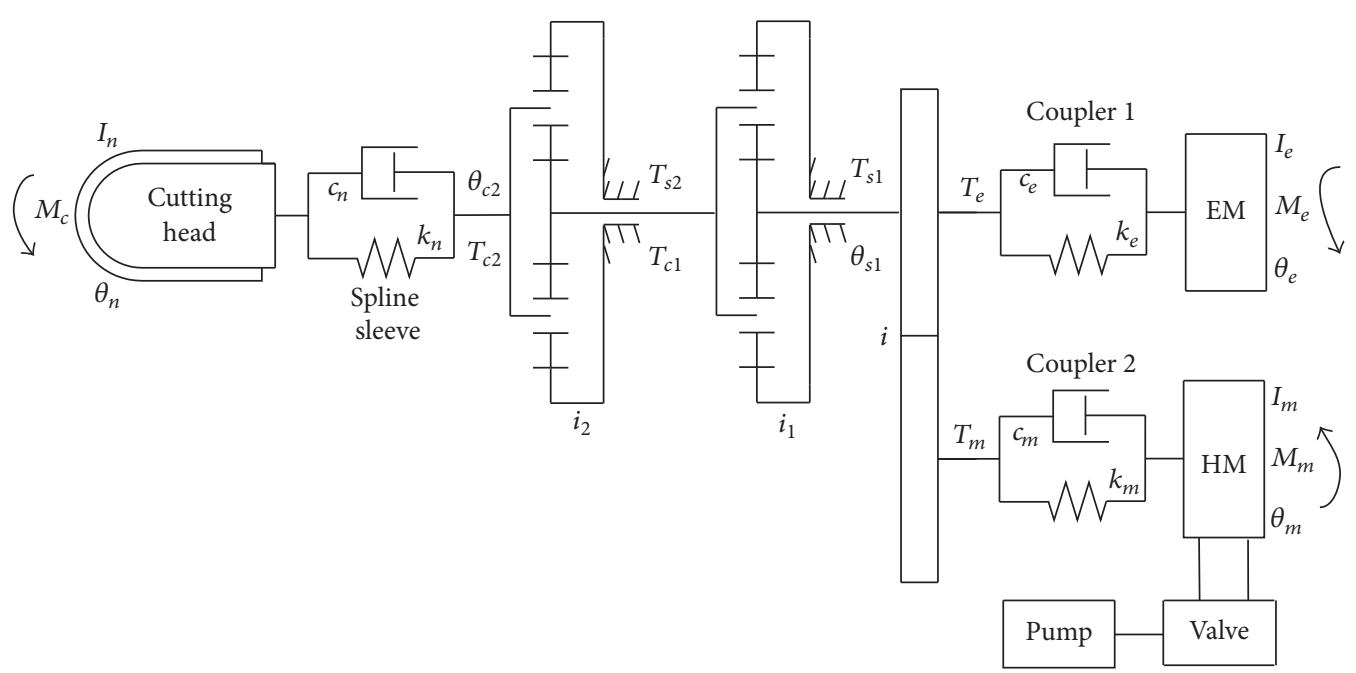

FIgURE 4: Dynamic model of the cutting system.

torque input to sun gear of first stage; $T_{s 2}$ is the torque input to the sun gear of second stage; $T_{c 2}$ is the torque output from carrier; $k_{e}$ and $c_{e}$ are the stiffness and damping of coupler 1 ; $k_{m}$ and $c_{m}$ are the stiffness and damping of coupler $2 ; k_{n}$ and $c_{n}$ are the stiffness and damping of spline sleeve; $\theta_{e}, \theta_{s 1}, \theta_{m}$, $\theta_{n}$, and $\theta_{c 2}$ are angular displacements of the EM, sun gear of the first-stage planetary, HM, cutting head, and carrier of the second-stage planetary, respectively; $i$ is the ratio of the coupling gears; $i_{1}$ and $i_{2}$ are the transmission ratios of twostage planetary set, respectively.

3.2. Electric Motor Model. Figure 5 depicts the equivalent circuit of the asynchronous electric motor. The mechanical characteristic of the asynchronous electric motor is derived as follows [14]:

$$
\begin{aligned}
P_{e} & =\frac{m_{1} U_{1}^{2} R_{2}^{\prime} / s}{\left(R_{1}+R_{2}^{\prime} / s\right)^{2}+\left(X_{1}+X_{2}^{\prime}\right)^{2}}, \\
M_{e} & =\frac{m_{1} p U_{1}^{2} R_{2}^{\prime} / s}{2 \pi f_{1}\left[\left(R_{1}+R_{2}^{\prime} / s\right)^{2}+\left(X_{1}+X_{2}^{\prime}\right)^{2}\right]}, \\
M_{e \max } & =\frac{m_{1} p U_{1}{ }^{2}}{4 \pi f_{1}\left(X_{1}+X_{2}^{\prime}\right)},
\end{aligned}
$$

where $P_{e}$ is the electromagnetic power, $M_{e}$ is the electromagnetic torque, $M_{e \max }$ is the maximum of the electromagnetic torque, $m_{1}$ is the phase number, $U_{1}$ is the phase voltage, $s$ is the slip ratio, $R_{1}$ is the stator resistance, $R_{2}^{\prime}$ is the equivalent rotor resistance, $X_{1}$ is the stator leakage reactance, $X_{2}^{\prime}$ is the equivalent rotor leakage reactance, $p$ is the pole pairs, and $f_{1}$ is the stator current frequency.

3.3. Dynamic Model of Planetary Gear Set. Figure 6 shows the purely torsional transmission model of single-stage planetary gear set in which only rotating degree of freedom is considered. We assume that each planet gear has the same mass

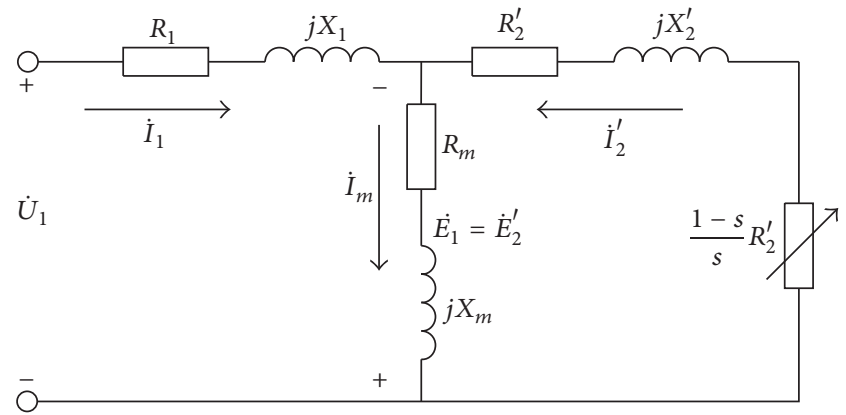

FIgURE 5: Circuit of the asynchronous electric motor.

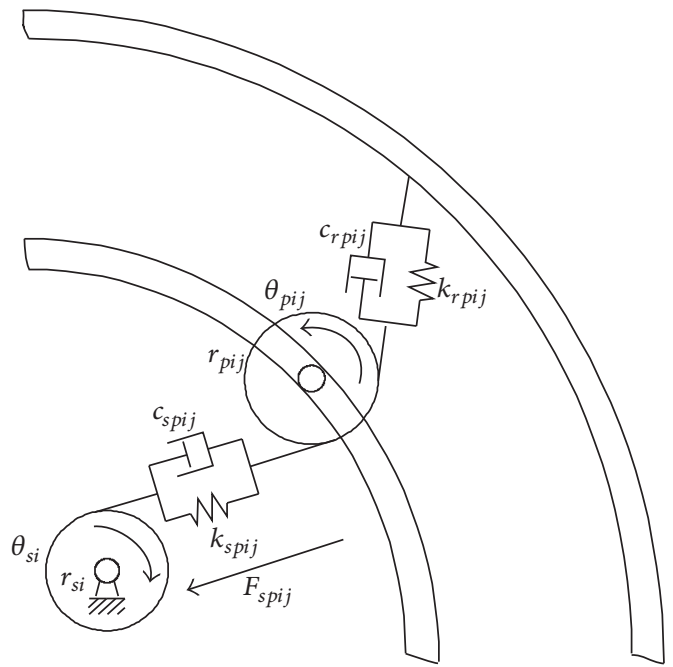

FIGURE 6: Purely torsional model of single-stage planetary gear set.

and rotary inertia. Gear backlash and motion transmission error are ignored here. $\theta$ is the angular displacement of each component, $I$ is the rotary inertia, and $F$ is the contact force. Corner marks of $s, p, c, r, i(i=1,2), j(j=1,2, \ldots, n, n=3$ 


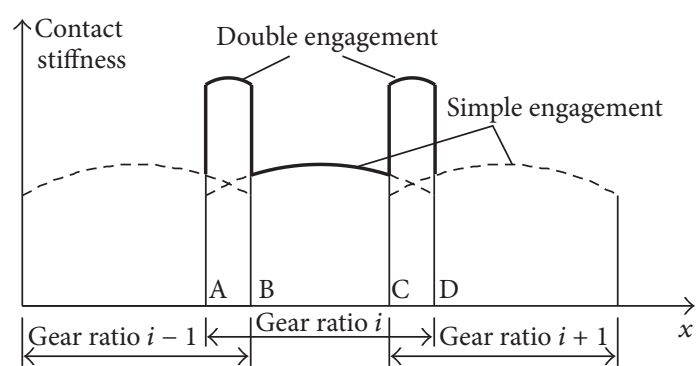

FIgURe 7: Periodic variation of contact stiffness.

when $i=3$ and $n=4$ when $i=2$ ) represent sun gear, planet gear, carrier, ring, stage number of planetary set, and planet gear number, respectively.

Dynamics equations of planetary gears are shown as follows where lumped mass methodology is utilized [15]:

$$
\begin{gathered}
I_{s i} \ddot{\theta}_{s i}=T_{s i}+\sum_{j=1}^{n} F_{s p i j} r_{s i}, \\
I_{r i} \ddot{\theta}_{r i}=\sum_{j=1}^{n} F_{r p i j} r_{r i}, \\
\left(I_{c i}+n I_{p i j}\right) \ddot{\theta}_{c i}=-\sum_{j=1}^{n}\left(F_{s p i j}+F_{r p i j}\right) r_{c i}+T_{c i}, \\
I_{p i j} \ddot{\theta}_{p i j}=F_{s p i j} r_{p i j}-F_{p r i j} r_{p i j} .
\end{gathered}
$$

Planetary gear set has two engagements including the engagement of sun-planet gear meshing (external-external gears) and the engagement of the ring-planet gear meshing (extern-internal gearing) [16, 17]. Stiffness excitation is a major internal incentive for gear engagement and gear meshing coincidence degree generally is a noninteger and greater than 1 . When involved in meshing teeth logarithm cycle changes over time, the meshing stiffness shows a stepwise periodic variation, as shown in Figure 7, $\mathrm{AD}$ is meshing line. Many studies use rectangular square wave to approximately replace varying stiffness, but it cannot represent the changes of meshing stiffness on engagement points.

Take external engagement between the sun gear and the planetary gear as an example, the meshing displacement of motion line between two teeth is defined as $\delta$,

$$
\frac{d \delta}{d t}=r_{s i} \dot{\theta}_{s i}-r_{p i j} \dot{\theta}_{p i j} .
$$

The dynamic meshing force along the direction of the action line is given by

$$
F_{s p i j}=k_{s p i j} \delta+c_{s p i j} \dot{\delta} .
$$

Meshing damping of tooth is defined as

$$
c_{p}=2 \xi_{g} \sqrt{\frac{k_{g} r_{1}^{2} r_{2}^{2} I_{1} I_{2}}{r_{1}^{2} I_{1}+r_{2}^{2} I_{2}}},
$$

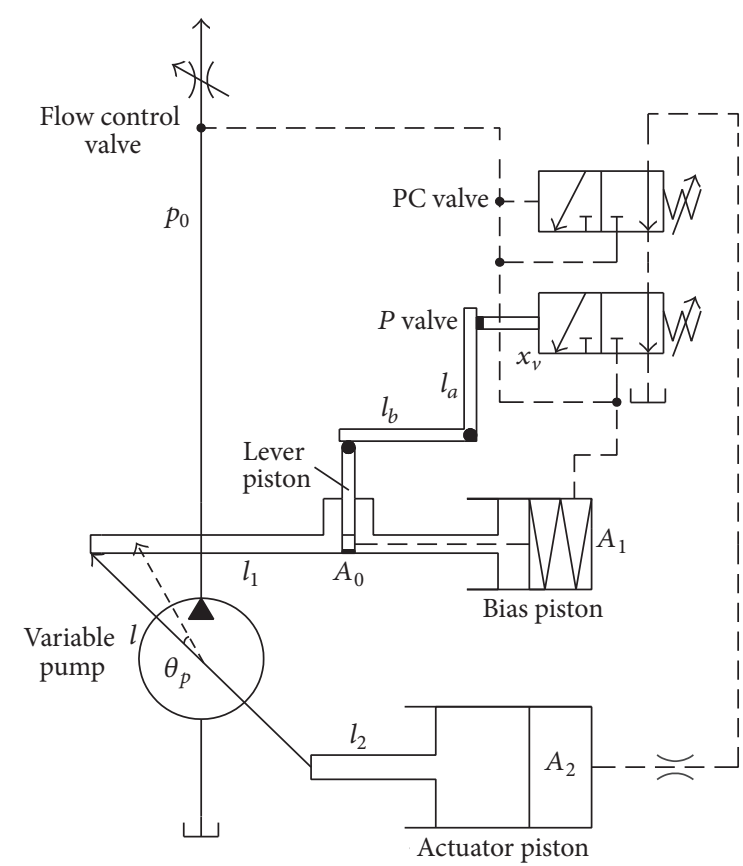

Figure 8: Variable pump with constant power control model.

where $\xi_{q}$ is tooth contact damping ratio and generally is 0.03 to $0.17 ; k_{g}$ is average meshing stiffness; $I_{i}$ is the moment of inertia of master gear, considering inertia is infinity when the ring is fixed.

When the ring is fixed, the meshing frequency of planetary gear train is given by

$$
\omega_{m}=\omega_{c} Z_{r}=\omega_{s} \frac{Z_{s} Z_{r}}{Z_{s}+Z_{r}}
$$

The phase position of engagement is given by

$$
x=\frac{Z_{r}}{2 \pi} \psi_{p} .
$$

In (10) and (11), $\omega_{c}$ is the rotating frequency of carrier and $\omega_{s}$ is rotational frequency of sun gear: $\omega_{s}=2 \pi n_{s} / 60$, where $n_{s}$ is the rotational speed of sun gear.

$$
k(x)=k_{2}+\frac{4}{\varepsilon_{\alpha}}\left(k_{1}-k_{2}\right) x-\frac{4}{\varepsilon_{\alpha}^{2}}\left(k_{1}-k_{2}\right) x^{2} .
$$

Comprehensive meshing stiffness can be expressed as

$$
K(x)= \begin{cases}k_{v}[k(x)+k(x+1)] ; & 0 \leq x \leq \varepsilon_{\alpha}-1 \\ k(x) ; & \text { else, }\end{cases}
$$

where $k_{1}$ is meshing stiffness of two pairs of teeth; $k_{2}$ is meshing stiffness of single pair of teeth; $\varepsilon_{\alpha}$ is coincidence degree; $k_{v}$ is stiffness correction coefficient.

3.4. Hydraulic System Models. Hydraulic system mainly consists of variable pump, directional valve, and HM. It can be divided into variable pump with constant power control model (Figure 8) and hydraulic motor controlled by fourdirectional valve model (Figure 9). A power control pump 


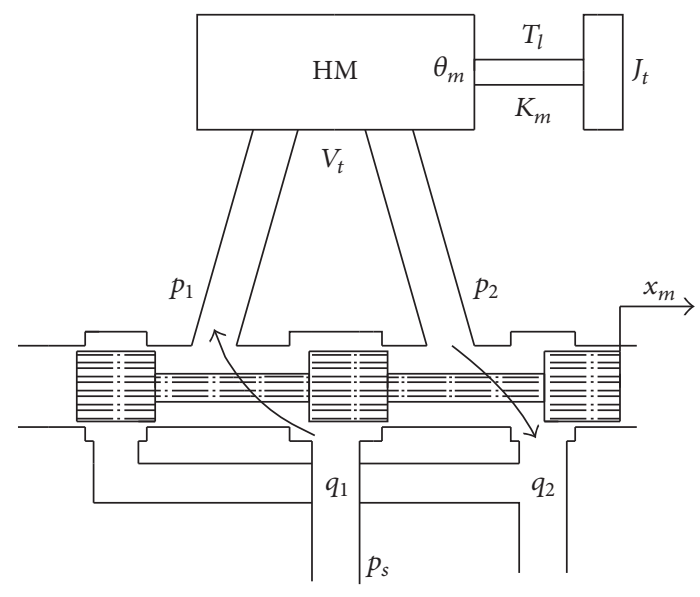

FIGURE 9: Hydraulic motor model controlled by four-direction valve.

with pressure cut-off is applied in this system. The pressure cut-off corresponds to a pressure control which adjusts the pump displacement back to $V_{g \text { min }}$, when the pressure setting is reached. This function overrides the power control; that is, below the preset pressure value, the power function is effective. The pump displacement locates at $V_{g \max }$ when the pump is not launched due to spring forces of the control valves [18-20]. We assume that

(1) the leakages of pump, motor, and valve are negligible;

(2) the spool valves are ideal with zero lapping;

(3) the valve restriction areas are linearly proportional to the spool opening;

(4) the damping forces and friction forces are neglected.

The force balance equation of the leverage which integrated into the $P$ valve (power control valve) module is expressed as

$$
F_{a} l_{a}=p_{s} A_{0} l_{b}
$$

where $F_{a}$ is the force that acts on the left of $P$ valve; $l_{a}$ is the arm between $P$ valve and leverage; $l_{b}$ is the arm between mandrills; $p_{s}$ is the pump discharge pressure; $A_{0}$ is the mandrill area.

The dynamics differential equation of $P$ valve is given as

$$
F_{a}-F_{0}=m_{v} \frac{d^{2} x_{v}}{d t^{2}}+K_{v} x_{v}
$$

where $F_{0}$ is the $P$ valve preset spring force; $m_{v}$ and $x_{v}$ are the mass and displacement of $P$ valve spool; $K_{v}$ is the $P$ valve spool spring constant.

The motion equation of the swash plate is represented by

$$
x_{p}=l \times \sin \theta_{p},
$$

where $x_{p}$ is the bias piston displacement; $l$ is the distance between the hinge point of swash plate and the application point of bias piston; $\theta_{p}$ is the swash plate angle.
The flow increment equation of the variable pump can be written as

$$
Q_{p}=-K_{\mathrm{Q}} n x_{p},
$$

where $Q_{p}$ is the pump output flow; $K_{Q}$ is the displacement gradient of pump; $n$ is the rotary speed of the pump.

The pressure characteristic equation of the pump can be derived as

$$
-Q_{p}+Q_{L}=\frac{V_{t}}{\beta_{p}} \cdot \frac{d p_{s}}{d t},
$$

where $Q_{L}$ is the load flow; $V_{t}$ is the pump output end volume; $\beta_{p}$ is the pump bulk modulus.

As depicted in Figure 9, it is the hydraulic motor controlled by four-directional valve model [21]. The flow equation of the four-directional valve is given as

$$
Q_{L}=K_{q m} x_{m}-K_{p m} p_{L},
$$

where $Q_{L}$ is the load flow, $Q_{L}=\left(q_{1}+q_{2}\right) / 2 ; K_{q m}$ and $K_{p m}$ are the flow gain and flow-pressure coefficient of the four-directional valve; $x_{m}$ is the four-directional valve spool displacement; $p_{L}$ is the load pressure, $p_{L}=p_{1}-p_{2}$.

The flow continuity equation of HM is expressed as

$$
Q_{L}=D_{m} \frac{d \theta_{m}}{d t}+\frac{V_{m}}{4 \beta_{e}} \frac{d p_{L}}{d t},
$$

where $D_{m}$ is the HM displacement; $\theta_{m}$ is the HM rotary speed; $V_{m}$ is the HM compression volume.

The torque balance equation of HM is represented as

$$
p_{L} D_{m}=I_{m} \frac{d^{2} \theta_{m}}{d t^{2}}+c_{m} \frac{d \theta_{m}}{d t}+k_{m} \theta_{m}+T_{m}
$$

where $I_{m}$ is the inertia of HM.

3.5. Model of the Cutting Head. In order to analyze the working characteristic of the new cutting system under different working conditions, load that acts on cutting head is modeled, which is the resultant force (torque) of each cutting pick [22]. The resistance on each pick can be calculated as

$$
Z_{i}=p_{k}\left[k_{T} k_{g} k_{y}\left(0.25+0.018 S_{i} h_{i}\right)+0.1 S_{d}\right] \text {, }
$$

where $p_{k}$ is the contact strength of the coal and rock, $k_{T}$ is the pick type, $k_{g}$ is the pick geometry, $k_{y}$ is the pick angle coefficient, $S_{i}$ is the distance between $i$ th cutting line and $i+1$ th, $S_{d}$ is the projection area of pick back-edge after dull along the line of traction, $h_{i}$ is the pick cutting thickness at any position which is given by

$$
h_{i}=\frac{1000 v}{n m} \sin \varphi_{i}
$$

where $v$ is the cutting speed at horizontal direction; $n$ is the rotating speed of cutting head; $m$ is the number of picks at one cutting line.

The torque load $M_{c}$ can be calculated by

$$
M_{c}=\sum_{i=1}^{n_{j}} Z_{i} r_{i}
$$

where $n_{j}$ is the pick number at some state, $r_{i}$ is the working radius of $i$ th pick. 

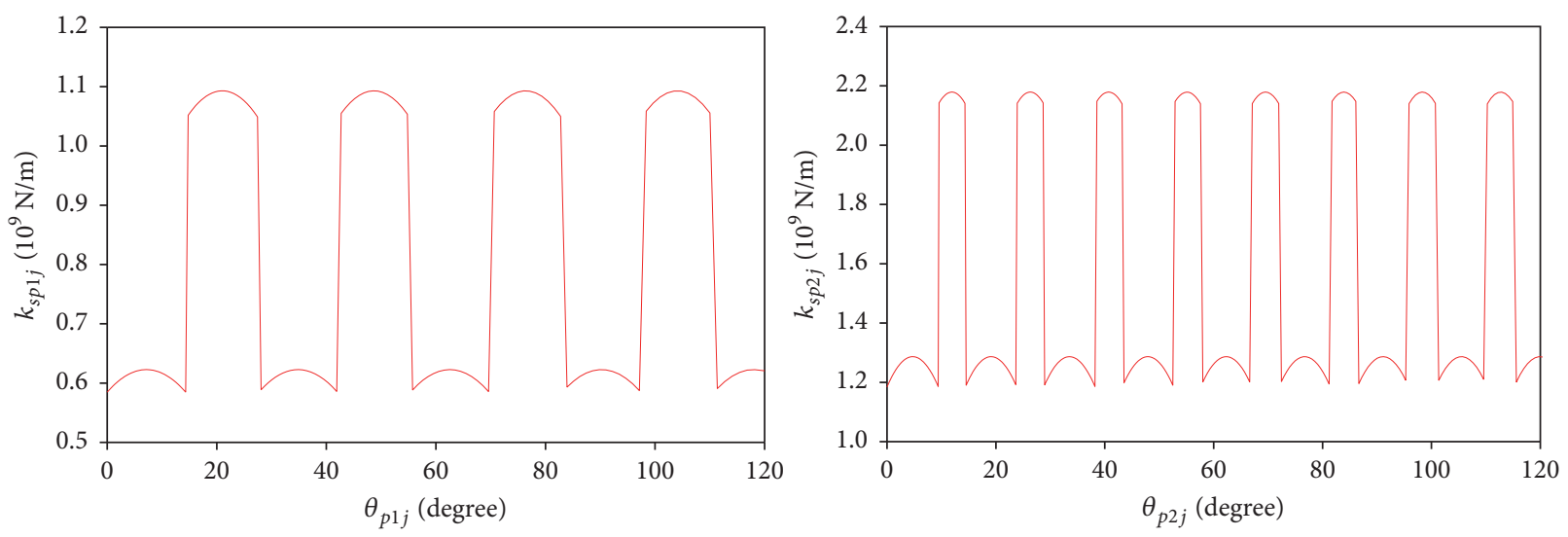

FIgURE 10: Variable contact stiffness of sun-planet gear.

TABLE 1: Parameters of the new hybrid power cutting system.

\begin{tabular}{lcc}
\hline & Parameters & Value \\
\hline & Phase number & 3 \\
Electric motor & Number of pole pairs & 3 \\
& Stator current frequency $[\mathrm{Hz}]$ & 1140 \\
\hline & Phase voltage $[\mathrm{V}]$ & 80 \\
Hydraulic motor & Displacement $[\mathrm{ml} / \mathrm{r}]$ & 3900 \\
& Maximum speed $[\mathrm{rpm}]$ & 25 \\
Cutting head & Circuit pressure $[\mathrm{MPa}]$ & 500 \\
& Inertia of cutting head $\left[\mathrm{kgm}{ }^{2}\right]$ & $10^{9}$ \\
& Stiffness of spline sleeve $[\mathrm{Nm} / \mathrm{rad}]$ & $10^{2}$ \\
\hline
\end{tabular}

\section{Simulation and Analysis}

The parameters of new hybrid power cutting system are shown in Table 1 . The parameters of gear transmission are given in Table 2.

According to GB3480-1997 and Table 2, the maximum meshing stiffness, the minimum meshing stiffness, the average meshing stiffness and damping of the meshing gear can be calculated, as shown in Table 3 .

Combining above data and formulas, in two-stage planetary gear train, the changes of the time-varying meshing stiffness $k_{\text {spij }}$ of sun-planet gear are shown in Figure 10 when the planetary rotation angle $\theta_{p i j}$ turns from $0^{\circ}$ to $120^{\circ}$.

4.1. Working Modes Analysis for New System as under Different Load Conditions. Considering the effects of cutting picks, three different working conditions with rock hardness $f=7$, 8,9 are modeled as shown in the left of Figure 11. The right of Figure 11 shows the output power of HM and EM on each condition; the figures have two $y$-axial where the blue line denotes the power of EM and the green line denotes the power of HM. As is shown in Figure 11(a), the torque load fluctuates from $59.2 \mathrm{kNm}$ to $61 \mathrm{kNm}$. The $\mathrm{HM}$ provides an auxiliary power with $0 \sim 5 \mathrm{~kW}$ to maintain the constant power output of EM when the torque load is over to the rated load $\left(M_{c}=60 \mathrm{kNm}\right)$. On the contrary, when the torque load is under rated load, the HM does not work and the EM works below its rated power.

Under the condition of $f=8$, the torque load fluctuates from $69 \mathrm{kNm}$ to $71.2 \mathrm{kNm}$. The output power of HM changes with the load but the output power of EM has a constant value. The total cutting power comes to $284 \mathrm{~kW}$ maximal. Under the condition of $f=9$, the torque load fluctuates from $80.1 \mathrm{kNm}$ to $82.4 \mathrm{kNm}$. The load is out of control of HM; as a result, the $\mathrm{HM}$ works at its max displacement with $52 \mathrm{~kW}$ output power and the EM works in the state of overload. The total cutting power comes to $325 \mathrm{~kW}$ maximal, but it is harmful to the EM if it works for a long time under this condition.

4.2. Dynamic Characteristics of the Cutting Motor. The shock load is shown in Figure 12 which has a step transformation from $60 \mathrm{kNm}$ to $80 \mathrm{kNm}$ at $t=2 \mathrm{~s}$. Figure 13 shows the cutting motor output speed variation of the traditional cutting systems and the hybrid power systems in $1.9 \sim 2.2 \mathrm{~s}$ under shock load, where the red line indicates the new hybrid power cutting system and the blue line indicates the traditional cutting transmission. When the shock load acts on the cutting head, the speed of cutting motor will decrease and then return to a stable value and the cutting motor speed fluctuations of the new hybrid power cutting system are smaller. Figure 14 shows the cutting motor output torque variation of the traditional cutting systems and the 

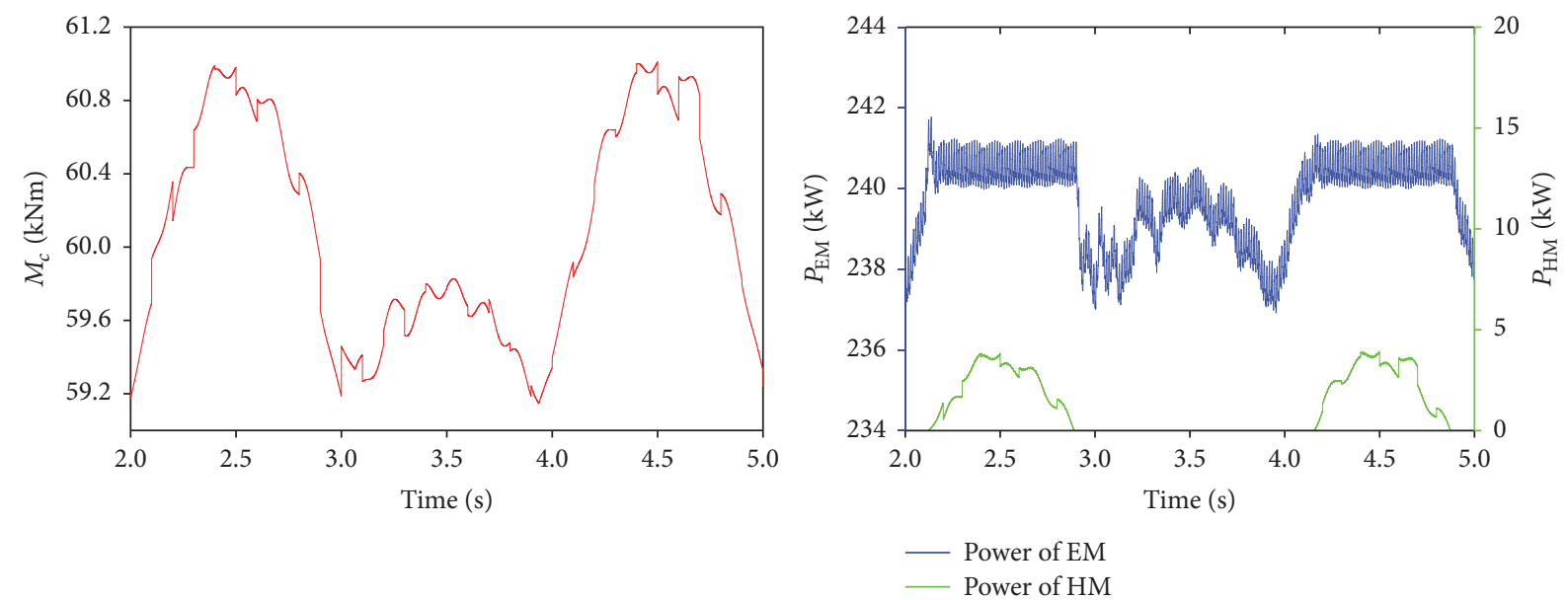

(a) $f=7$
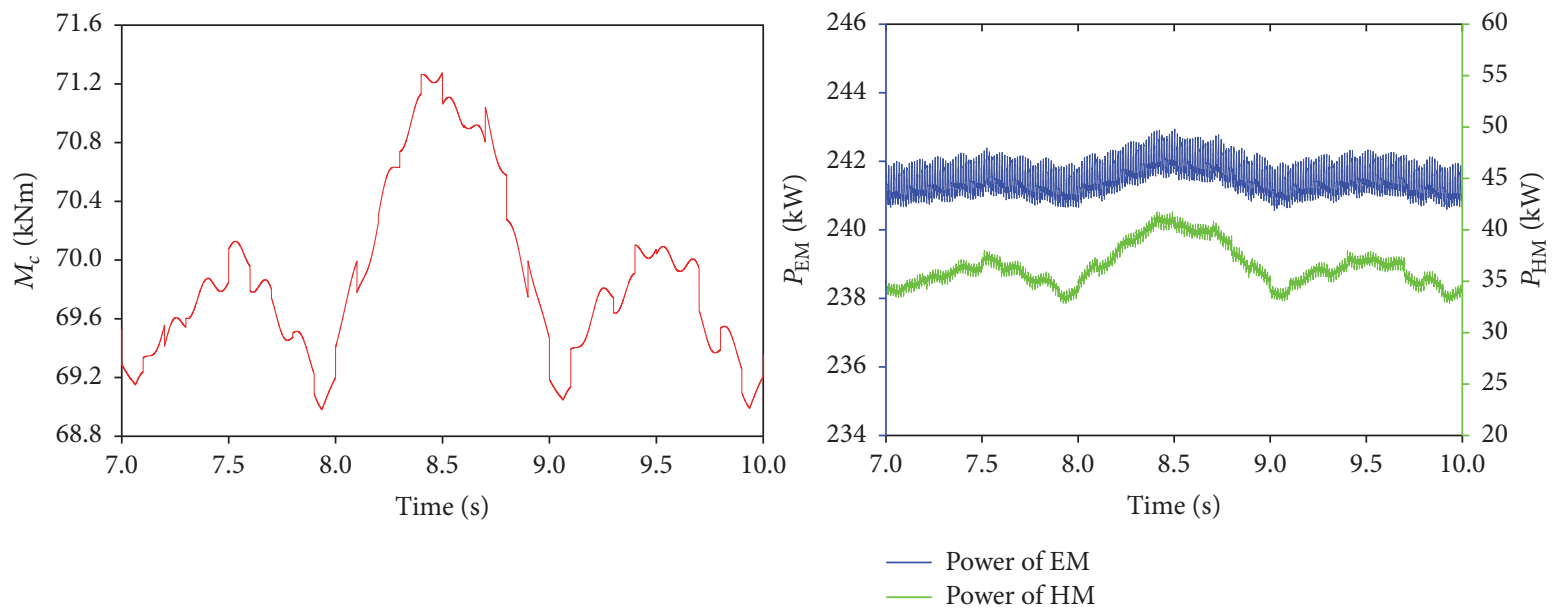

(b) $f=8$
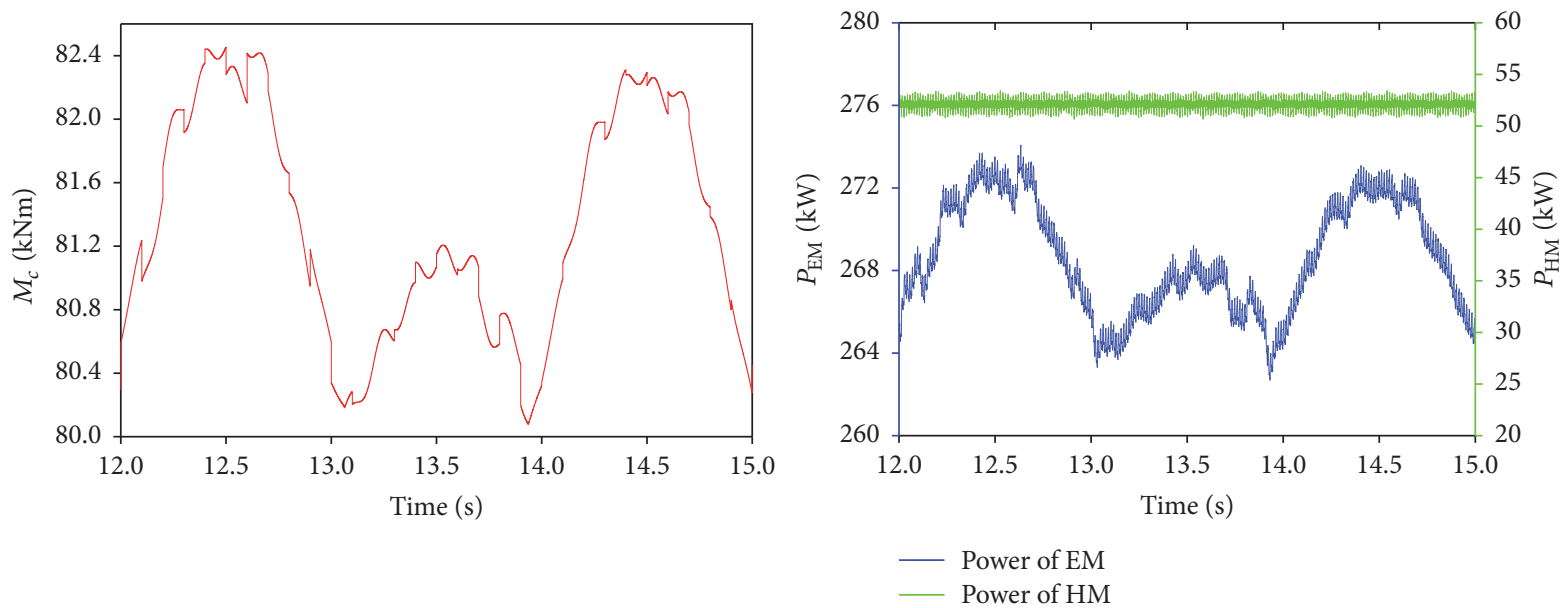

(c) $f=9$

FIGURE 11: Different load and output power of EM and HM.

hybrid power systems in 1.9 2.2 s, where Figure 14(a) shows the motor torque under constant stiffness (average meshing stiffness) and Figure 14(b) shows the motor torque under time-varying meshing stiffness. These figures show that, due to the effect of the auxiliary hydraulic motor, the new hybrid power system motor torque reduces by $21 \%$ compared with the traditional systems when the load is stable; the peak torque (A) of the new hybrid power system caused by the time-varying meshing stiffness is $73 \%$ of the traditional system (B) in the whole process. 
TABLE 2: Parameters of gear transmission.

\begin{tabular}{|c|c|c|c|c|c|c|c|c|}
\hline \multirow[b]{2}{*}{ Gear } & \multicolumn{2}{|c|}{ Coupler } & \multicolumn{3}{|c|}{ First-stage planetary gear set } & \multicolumn{3}{|c|}{ Secondary-stage planetary gear set } \\
\hline & 1 & 2 & $s$ & $p$ & $r$ & $s$ & $p$ & $r$ \\
\hline Transmission ratio & \multicolumn{2}{|c|}{1.55} & \multicolumn{3}{|c|}{5.538} & \multicolumn{3}{|c|}{4.960} \\
\hline Number of planets & \multicolumn{2}{|c|}{-} & \multicolumn{3}{|c|}{3} & \multicolumn{3}{|c|}{4} \\
\hline Module (m) & \multicolumn{2}{|c|}{6} & \multicolumn{3}{|c|}{6} & \multicolumn{3}{|c|}{6} \\
\hline Number of teeth & 45 & 29 & 13 & 23 & 59 & 25 & 37 & 99 \\
\hline Pressure angle $\left({ }^{\circ}\right)$ & \multicolumn{2}{|c|}{20} & \multicolumn{3}{|c|}{20} & \multicolumn{3}{|c|}{20} \\
\hline Teeth width (m) & \multicolumn{2}{|c|}{90} & \multicolumn{3}{|c|}{55} & \multicolumn{3}{|c|}{94} \\
\hline
\end{tabular}

TABLE 3: Internal parameters of planetary gear set.

\begin{tabular}{lcccc}
\hline & \multicolumn{2}{c}{ First-stage planetary gear set } & \multicolumn{2}{c}{ Secondary-stage planetary gear set } \\
& $s-p$ & $r-p$ & $s-p$ & $r-p$ \\
\hline$\varepsilon_{\alpha}$ & 1.517 & 1.785 & 1.655 & 1.839 \\
$k_{1}\left(\times 10^{9} \mathrm{~N} / \mathrm{m}\right)$ & 7.093 & 1.320 & 2.179 & 2.436 \\
$k_{g}\left(\times 10^{9} \mathrm{~N} / \mathrm{m}\right)$ & 0.867 & 1.198 & 1.857 & 2.268 \\
$k_{2}\left(\times 10^{9} \mathrm{~N} / \mathrm{m}\right)$ & 0.625 & 0.754 & 1.245 & 1.392 \\
$c_{p}(\mathrm{~N} /(\mathrm{m} / \mathrm{s}))$ & 8.889 & - & 115.948 & - \\
\hline
\end{tabular}

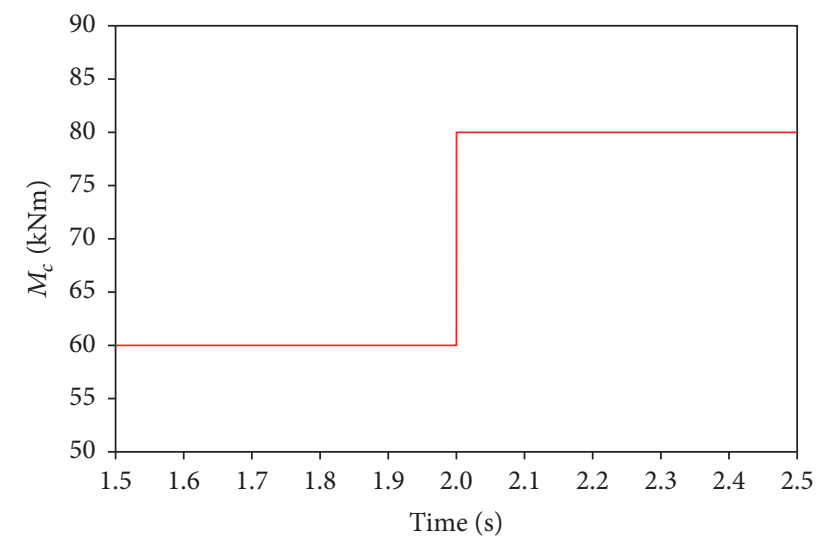

Figure 12: Shock load.

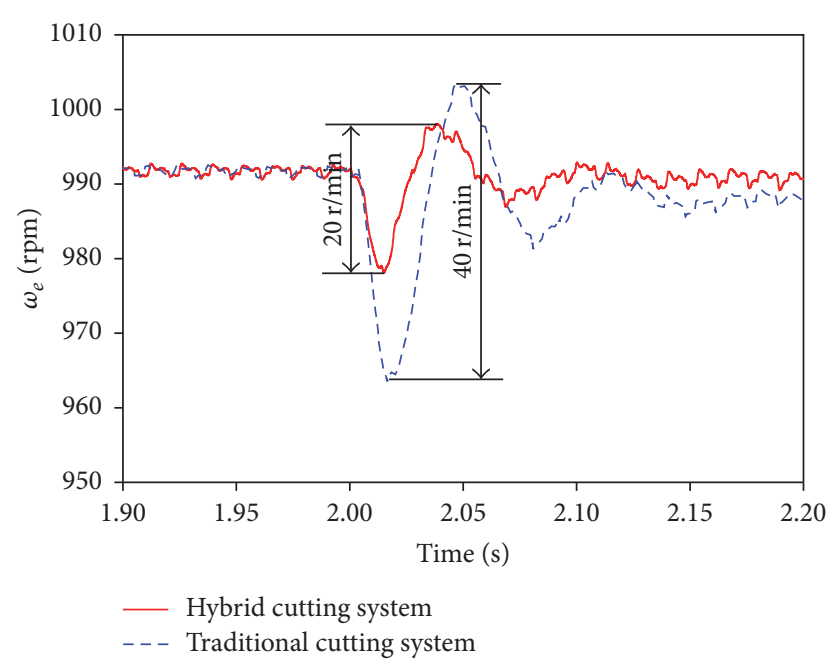

FIGURE 13: Output rotation speed of cutting motor.
TABLE 4: Stiffness and damping groups of the coupler connecting electric motor with coupling gear.

\begin{tabular}{lccccccc}
\hline Group & 1 & 2 & 3 & 4 & 5 & 6 & 7 \\
\hline$k_{e}(\mathrm{Nm} / \mathrm{rad})$ & $10^{4}$ & $10^{4}$ & $10^{3}$ & $10^{4}$ & $10^{5}$ & $10^{6}$ & $10^{4}$ \\
$c_{e}(\mathrm{Nm} /(\mathrm{rad} / \mathrm{s}))$ & 0 & 10 & $10^{2}$ & $10^{2}$ & $10^{2}$ & $10^{2}$ & $10^{3}$ \\
\hline
\end{tabular}

Dynamic meshing force is an important parameter for measuring the vibration and noise of gear transmission system. Figure 15 shows the dynamic meshing force of the sun-planet gear pair motivated by time-varying meshing stiffness under shock load, where $\left(\mathrm{A}_{1}\right)$ and $\left(\mathrm{C}_{1}\right)$ are the peaks of meshing force impact of the traditional cutting system; $\left(\mathrm{B}_{1}\right)$ and $\left(D_{1}\right)$ are the peaks of meshing forces of the new hybrid cutting system. When the shock load acts on cutting head at $t=2 \mathrm{~s}$, the meshing forces have an obvious increase. As the hydraulic circuit is a flexible system, the meshing force impact under shock load reduces significantly compared with the traditional system. Furthermore, this phenomenon is more obvious on the secondary-stage planetary gear train.

4.3. Influence of the Coupling Stiffness and Damping on Dynamic Meshing Forces. Coupling is an important connection component in power train. There are three couplings in the new cutting system: (1) connecting the electrical motor with coupling gear; (2) connecting the hydraulic motor with the coupling gear; (3) connecting reducer output with cutting head. This article takes the coupling connecting the motor with coupling gear as the object to analyze the effect of stiffness and damping on the dynamic meshing force under stable load $(t=0 \sim 2 \mathrm{~s})$ and shock load $(t=2 \mathrm{~s})$. The load is shown in Figure 12. As shown in Table 4, seven groups of different stiffness and damping are chosen. 


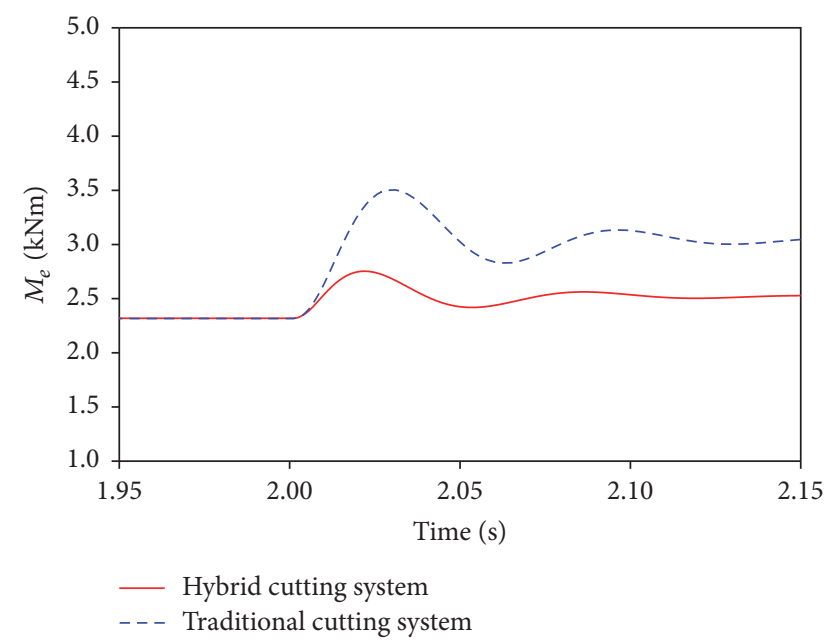

(a) Constant meshing stiffness

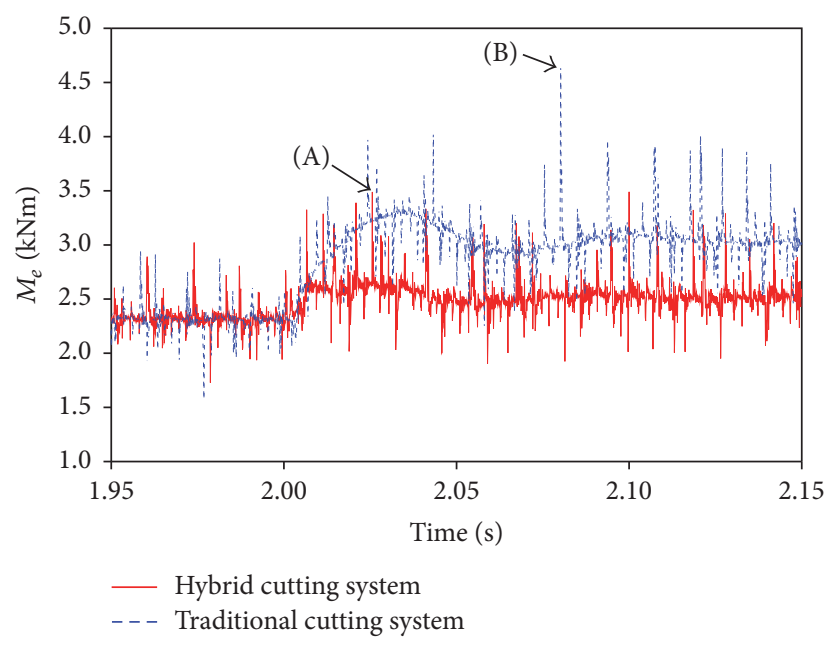

(b) Time-varying meshing stiffness

FIGURE 14: Output torque of cutting motor.

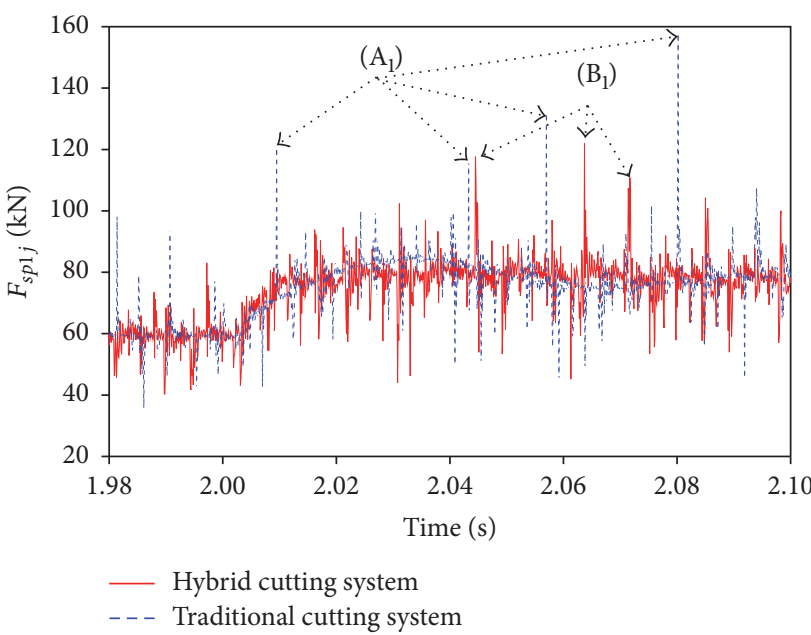

(a)

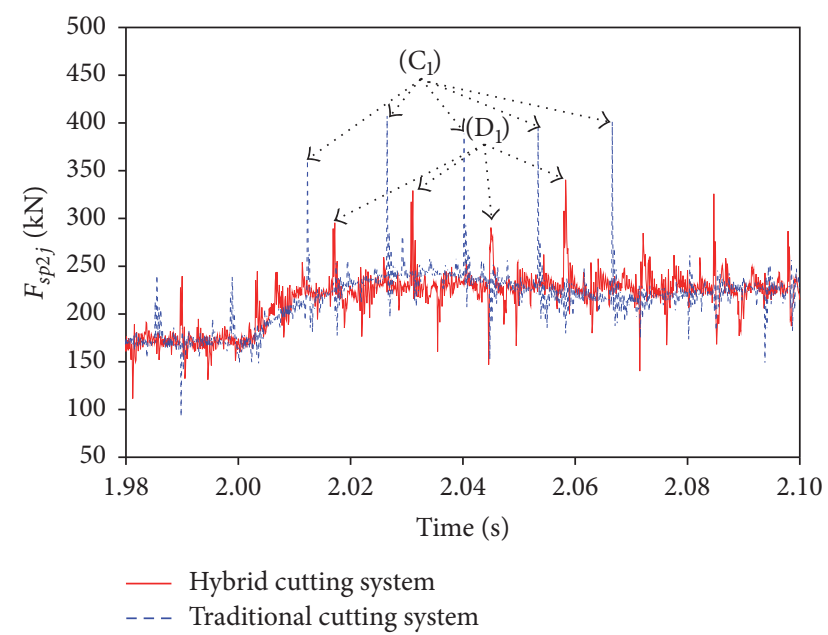

(b)

Figure 15: (a) Dynamic meshing force of the first-stage planetary gear. (b) Dynamic meshing force of the secondary-stage planetary gear.

Figure 16 shows the dynamic meshing force of sun-planet gear pair of two-stage planetary set caused by the coupling stiffness from $1.55 \mathrm{~s}$ to $1.6 \mathrm{~s}$. Under stable load, $k_{e}$ has small influence on the dynamic meshing forces and the peaks of meshing impact forces caused by the time-varying meshing stiffness are almost the same. Figure 17 shows the effect of damping on dynamic meshing force from $1.56 \mathrm{~s}$ to $1.58 \mathrm{~s}$ under stable load. It shows that the fluctuation of the dynamic meshing force is larger under undamped condition $(\mathrm{G} 1=0)$ than other groups and the damping has a conspicuous benefit to diminish the dynamic mesh force impact.

$F_{s p 2 j}$ is the dynamic meshing forces of the sun-planet gear in the secondary-stage planetary gear. Figure 18(a) shows the evolutions of $F_{s p 2 j}$ from $1.99 \mathrm{~s}$ to $2.03 \mathrm{~s}$ with different stiffness. A, B, C, and D are the peaks of meshing forces impact caused by shock load under different stiffness, respectively. As depicted in the picture, the meshing force impact is $200 \mathrm{kN}$ when stiffness is $10^{3} \mathrm{Nm} / \mathrm{rad}$, but $350 \mathrm{kN}$ when stiffness is $10^{6} \mathrm{Nm} / \mathrm{rad}$. Hence, the meshing force impact caused by shock load is proportional to stiffness. Figure 18(b) shows the evolutions of $F_{s p 2 j}$ with different damping, where $\mathrm{E}, \mathrm{F}$, and $\mathrm{G}$ are the peaks of meshing forces impact, respectively. It can be seen from the figure that the damping of coupler has an obvious effect on the peak of meshing impact forces of the sun-planet gear caused by the shock load. Compared with the other damping value (such as $10 \mathrm{Nm} /(\mathrm{rad} / \mathrm{s})$ and $\left.10^{3} \mathrm{Nm} /(\mathrm{rad} / \mathrm{s})\right)$, a suitable damping value (such as $10^{2} \mathrm{Nm} /(\mathrm{rad} / \mathrm{s})$ ) can suppress the peak of meshing impact forces of the sun-planet gear better. So, there is an optimal damping value when we choose the different models of coupling. 

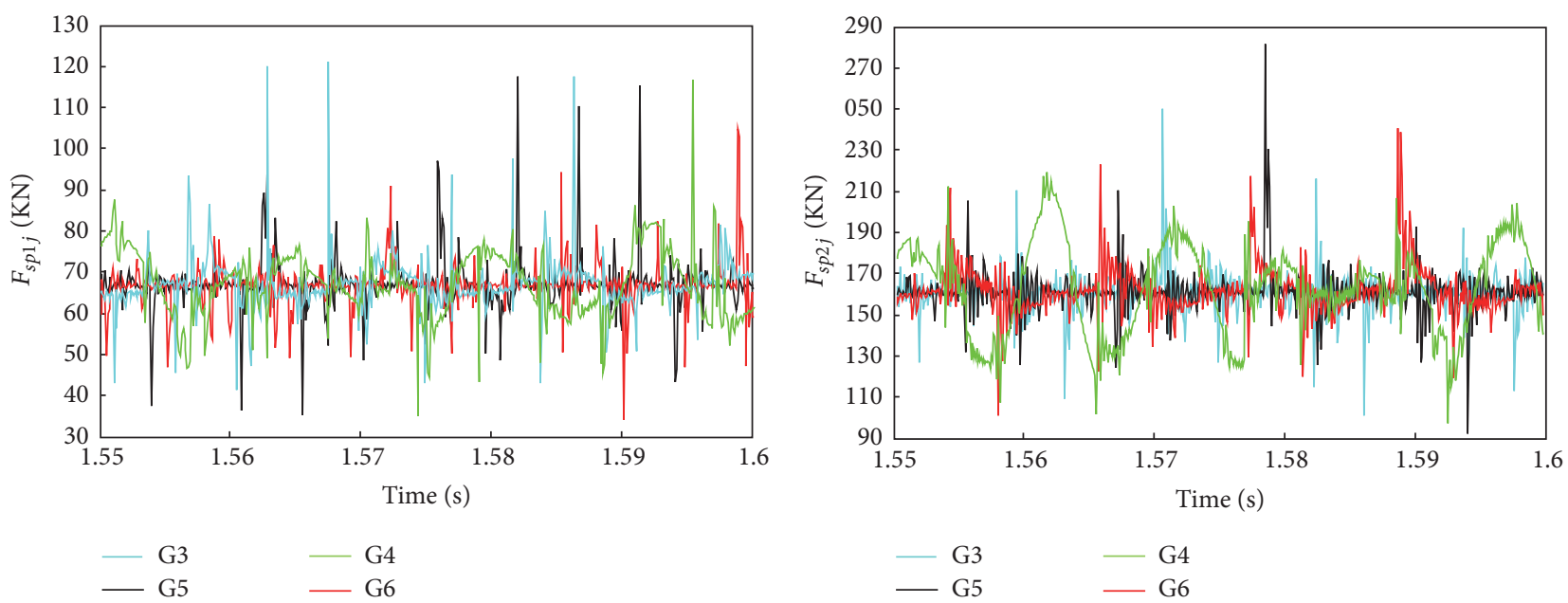

(a) $F_{s p 1 j}$

(b) $F_{s p 2 j}$

FIGURE 16: Dynamic meshing forces of the sun-planet gear with different stiffness under stable load.
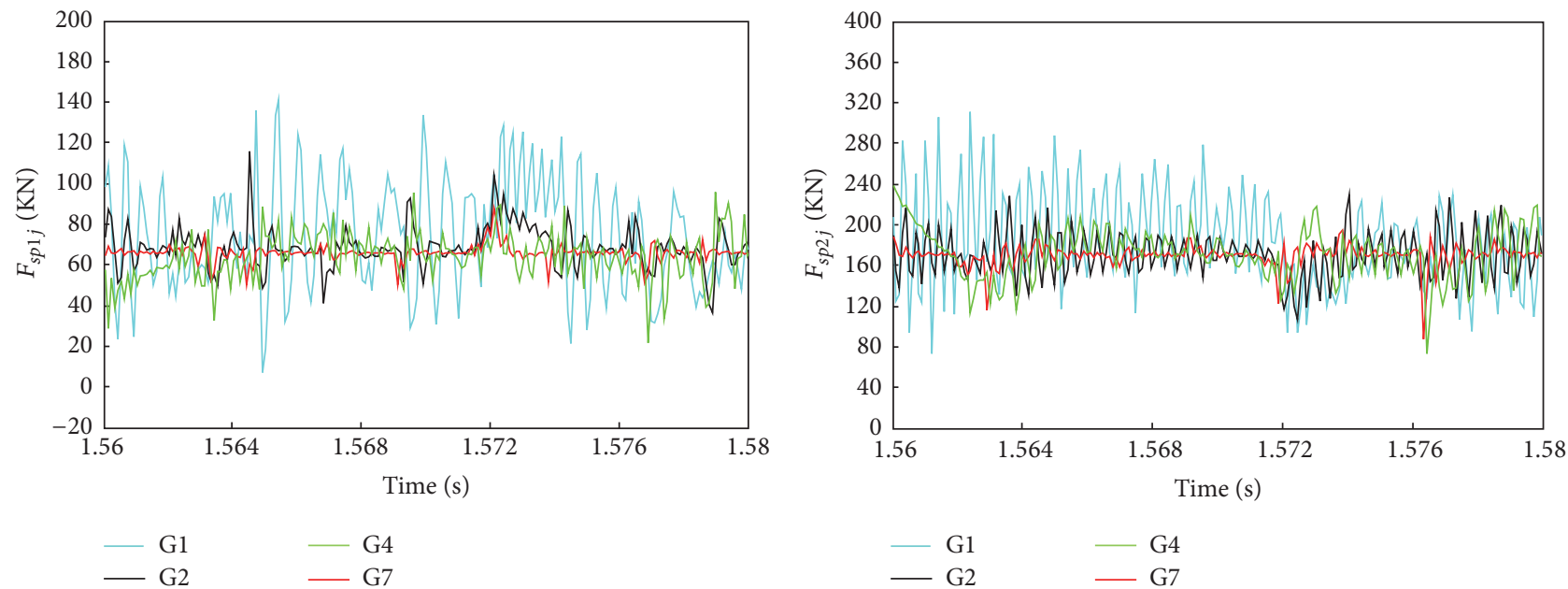

(a) $F_{s p 1 j}$

(b) $F_{s p 2 j}$

FIGURE 17: Dynamic meshing forces of the sun-planet gear with different damping of coupler 1 under stable load.
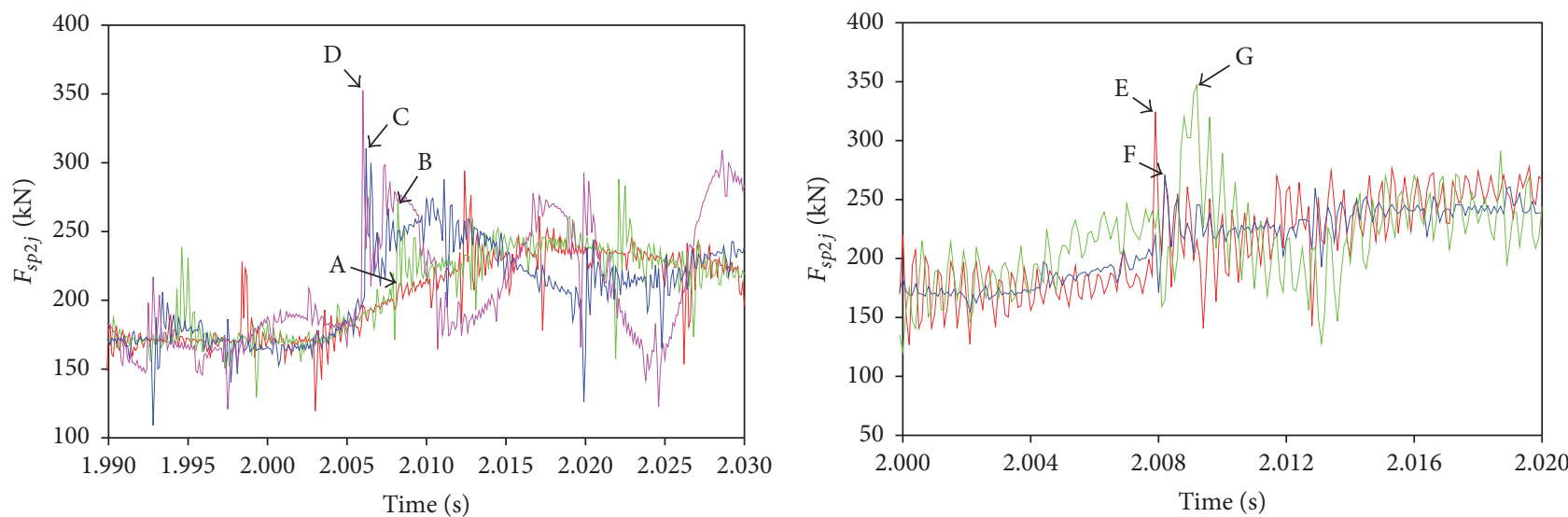

$\begin{array}{ll}\text { G3 } & -\mathrm{G} 5 \\ \mathrm{G} 4 & -\mathrm{G} 6\end{array}$

(a)

$-\mathrm{G} 2$

G7

(b)

FIGURE 18: $F_{s p 2 j}$ with different stiffness under shock load. $F_{s p 2 j}$ with different damping under shock load. 


\section{Conclusions}

In this paper, the overall model is discussed on specific conditions based on the authorized invention patent "Hybrid Power Transmission System of Roadheader." The auxiliary effects of variable hydraulic motor on different working conditions are investigated through numerical simulation. The main conclusions are summarized as follows:

(1) The HM can not only increase the total cutting power but also coordinate the power allocation to maintain the EM working at rated power point.

(2) A comparison between the new hybrid power cutting system and the traditional cutting system about their dynamic response characteristic under shock load is obtained. It shows that the dynamic impact caused by the shock load can be reduced obviously in the new hybrid power cutting system.

(3) The effects of stiffness and damping of couplings on the dynamic mesh force are also analyzed. Under stable load, the stiffness has little influence on the dynamic mesh force impact but the damping has a conspicuous benefit to diminish the dynamic mesh force impact. Under shock load, the dynamic mesh force impact is proportional to the stiffness and it does create a suitable damping. The results can be used to optimize the design of the hybrid power cutting transmission system, and they are also appropriate for the traditional roadheader machine.

\section{Conflicts of Interest}

The authors declare that they have no conflicts of interest.

\section{Acknowledgments}

The authors would like to acknowledge the support and contribution from the State Key Lab of Mechanical Transmission, Chongqing University, China. This research was funded by the National Major Basic Research Program of China (973 Program, Grant no. 2014CB046304).

\section{References}

[1] Y. Yang, X. Li, D. Qin et al., "Hybrid power transmission system of roadheader: China," ZL201410227930.0, 2016.

[2] I. Ocak and N. Bilgin, "Comparative studies on the performance of a roadheader, impact hammer and drilling and blasting method in the excavation of metro station tunnels in Istanbul," Tunnelling and Underground Space Technology, vol. 25, no. 2, pp. 181-187, 2010

[3] M.-C. He, H.-P. Xie, S.-P. Peng, and Y.-D. Jiang, "Study on rock mechanics in deep mining engineering," Chinese Journal of Rock Mechanics and Engineering, vol. 24, no. 16, pp. 2803-2813, 2005.

[4] Y.-N. He, L.-J. Han, P. Shao, and B.-S. Jiang, "Some problems of rock mechanics for roadways stability in depth," Journal of China University of Mining and Technology, vol. 35, no. 3, pp. 287-295, 2006.
[5] H. Kang and L. Si, "Test and analysis of coal and rock mass strength in deep coal mine," Chinese Journal of Rock Mechanics and Engineering, vol. 28, no. 7, pp. 1312-1320, 2009.

[6] R. Comakli, S. Kahraman, and C. Balci, "Performance prediction of roadheaders in metallic ore excavation," Tunnelling and Underground Space Technology, vol. 40, pp. 38-45, 2014.

[7] A. Ebrahimabadi, K. Goshtasbi, K. Shahriar, and M. C. Seifabad, "A universal model to predict roadheaders' cutting performance," Archives of Mining Sciences, vol. 57, no. 4, pp. 1015-1026, 2012.

[8] N. Bilgin, T. Dincer, H. Copur, and M. Erdogan, "Some geological and geotechnical factors affecting the performance of a roadheader in an inclined tunnel," Tunnelling and Underground Space Technology, vol. 19, no. 6, pp. 629-636, 2004.

[9] C. Balci, M. A. Demircin, H. Copur, and H. Tuncdemir, "Estimation of optimum specific energy based on rock properties for assessment of roadheader performance," Journal of The South African Institute of Mining and Metallurgy, vol. 104, no. 11, pp. 633-642, 2004.

[10] L.-J. Zhao, Z. Tian, Y. Sun, and Z.-H. Zhou, "Vibration characteristics of a longitudinal roadheader," Journal of Vibration and Shock, vol. 32, no. 11, pp. 17-20, 2013.

[11] M. Huang, G. Li, M. Wu, and W. An, "Vibration measurement and modal analysis of boom type tunneller," Mining Technology, vol. 112, no. 1, pp. 69-72, 2003.

[12] S. Okubo and Y. Nishimatsu, "Fundamental study on vibration of roadheader," Nihon Kogyokaishi, vol. 104, no. 1210, pp. 891896, 1988.

[13] M. Mohammadpour, S. Theodossiades, and H. Rahnejat, "Dynamics and efficiency of planetary gear sets for hybrid powertrains," Proceedings of the Institution of Mechanical Engineers, Part C: Journal of Mechanical Engineering Science, vol. 230, no. 7-8, pp. 1359-1368, 2015.

[14] S. J. Chapman and Y. Man, Electric Machinery Fundamentals, Tata McGraw-Hill Education, Beijing, China, 2008.

[15] A. Kahraman, "Natural modes of planetary gear trains," Journal of Sound and Vibration, vol. 173, no. 1, pp. 125-130, 1994.

[16] J. Lin and R. G. Parker, "Mesh stiffness variation instabilities in two-stage gear systems," Journal of Vibration and Acoustics, Transactions of the ASME, vol. 124, no. 1, pp. 68-76, 2002.

[17] M. T. Khabou, N. Bouchaala, F. Chaari, T. Fakhfakh, and M. Haddar, "Study of a spur gear dynamic behavior in transient regime," Mechanical Systems and Signal Processing, vol. 25, no. 8, pp. 3089-3101, 2011.

[18] M. J. G. T. Tonyan, Electronically Controlled Proportional Valves: Selection and Application, M. Dekker, New York, NY, USA, 1985.

[19] R. B. Walters, Hydraulic and Electric-Hydraulic Control Systems, Kluwer Academic Publishers, Dordrecht, The Netherlands, 2000.

[20] K. Dasgupta and H. Murrenhoff, "Modelling and dynamics of a servo-valve controlled hydraulic motor by bondgraph," Mechanism and Machine Theory, vol. 46, no. 7, pp. 1016-1035, 2011.

[21] Y. Wang, "Modeling and control for variable-pump controlling variable-motor," Control Theory and Applications, vol. 29, no. 1, pp. 41-46, 2012.

[22] X.-H. Li, Y. He, T. Li, and T.-T. Yang, "Analysis of horizontal and vertical random vibration responses of longitudinal roadheader," Meitan Xuebao/Journal of the China Coal Society, vol. 39, no. 3, pp. 580-585, 2014. 


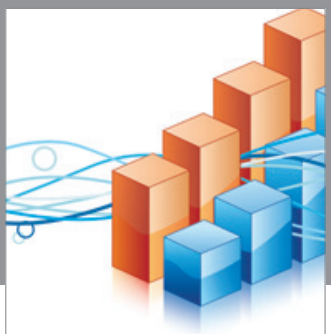

Advances in

Operations Research

vatem alat4

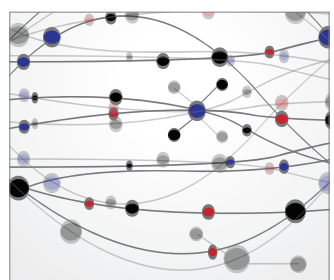

\section{The Scientific} World Journal
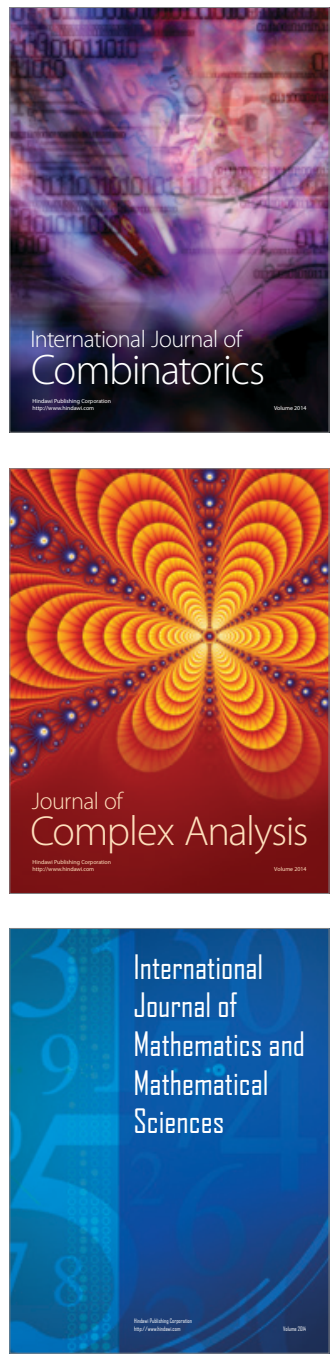
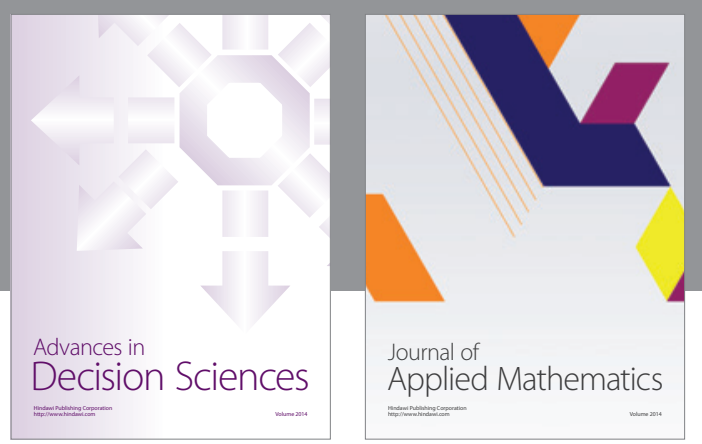

Algebra

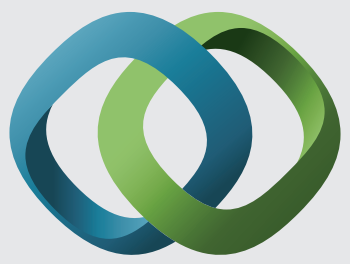

\section{Hindawi}

Submit your manuscripts at

https://www.hindawi.com
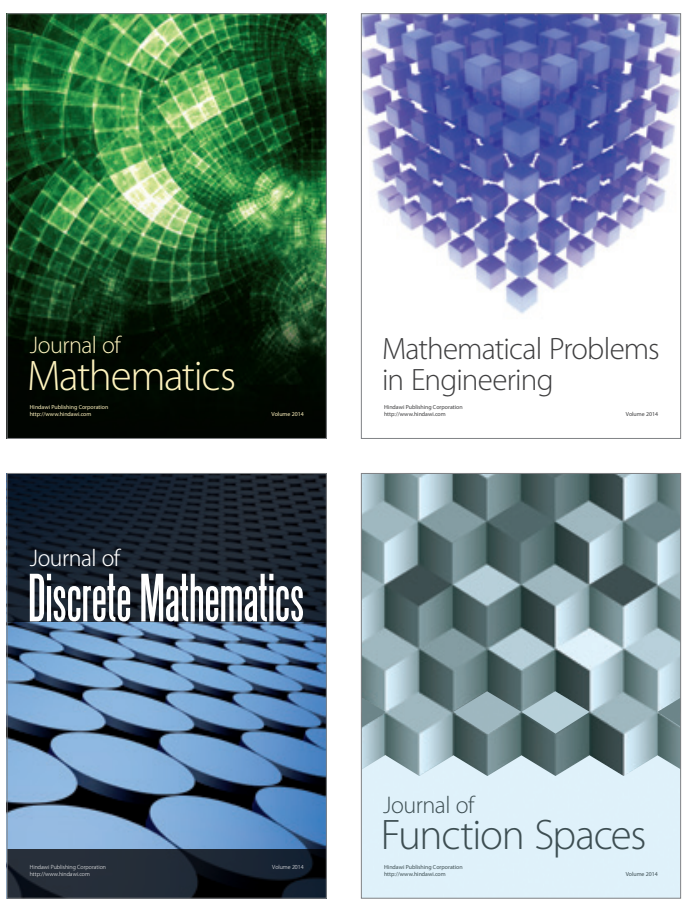

Mathematical Problems in Engineering
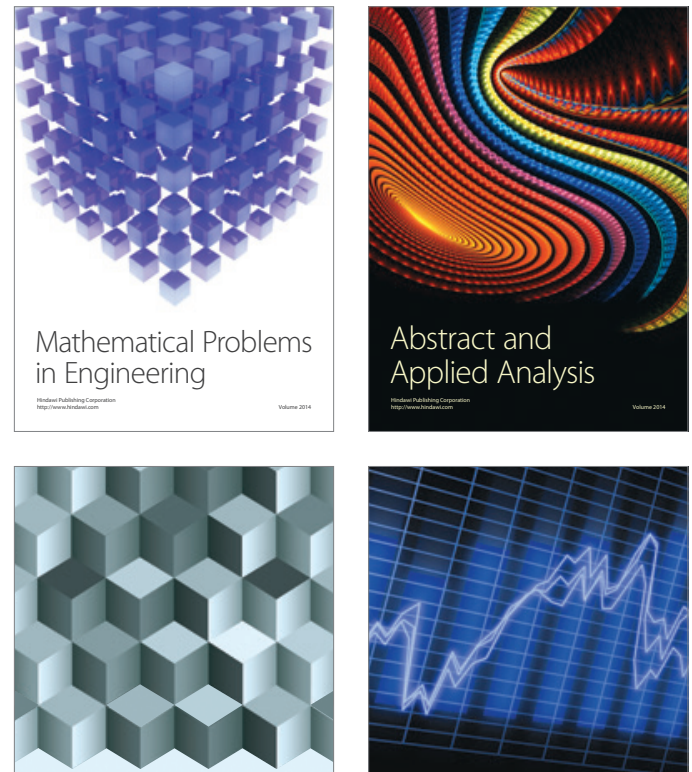

Journal of

Function Spaces

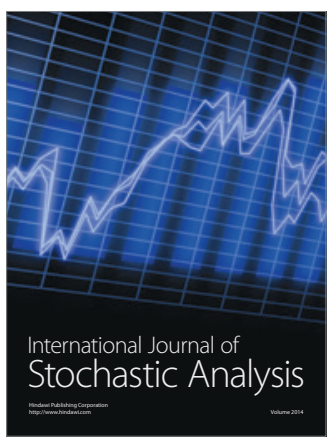

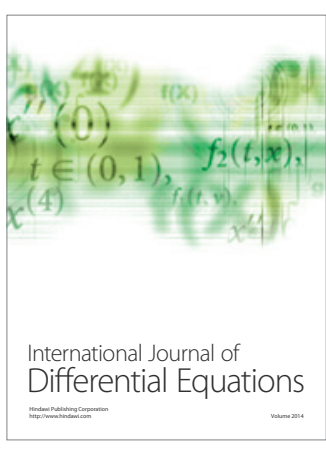
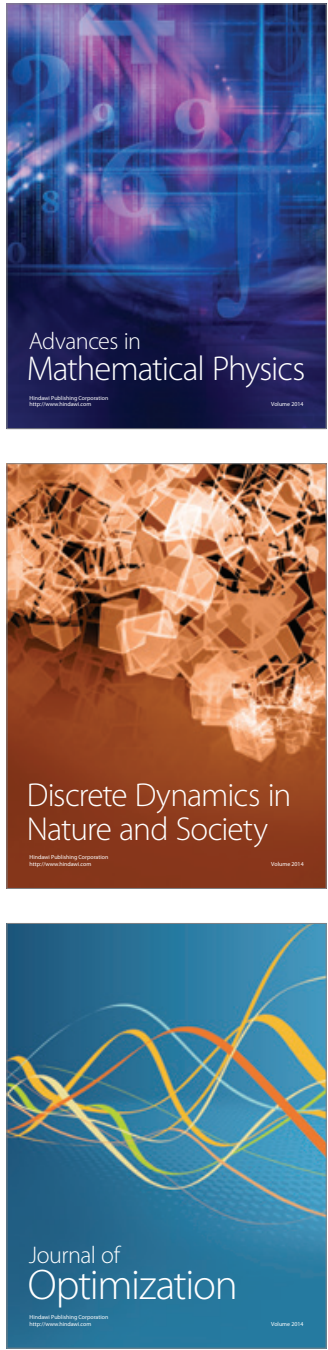